\title{
Amino Acid Ratio Measurement
}

National Cancer Institute

\section{Source}

National Cancer Institute. Amino Acid Ratio Measurement. NCI Thesaurus. Code C81185.

The determination of the ratio of one amino acid compared to another amino acid present in a sample. The measurement may be expressed as a ratio or percentage. 